\title{
Study of the Cytotoxicity Effect of Doxorubicin-loaded/Folic acid-Targeted Super Paramagnetic Iron Oxide Nanoparticles on AGS Cancer Cell Line
}

\author{
Mohammed Ghanbari ${ }^{*}$, Asadollah Asadi' and Somayyeh Rostamzadeh ${ }^{2}$
}

${ }^{1}$ Department of Biology, Faculty of Science, University of Mohaghegh Ardabili, Ardabil, Iran

${ }^{2}$ Department of Chemistry, Faculty of Sciences, Islamic Azad University, Ardabil, Iran

\begin{abstract}
Doxorubicins (Dox), a type of antibiotic and very effective anti-neoplastic agent, are routinely used in the treatment of cancers. The purpose of this research is to design a drug delivery system based on folic acid-targeted magnetic iron oxide nanoparticles and doxorubicin And also investigation of biological activity of doxorubicin in free mode and loaded onto the nanoparticles on cancer cell line is the another purpose of this research. Dox loading on iron oxide nanoparticles was performed by adsorption of its solution. Cytotoxicity of Dox, in free and loaded onto the nanoparticles, on gastric cancer cell line (AGS) was performed and compared by MTT assay. The morphological Studies of cells were performed with inverted microscope and fluorescence microscopy was used to study the penetration of nanoparticles in cells. The results of spectroscopic studies of UV/Visible and infrared diffuse reflectance spectroscopy (DRS) confirmed the binding of doxorubicin (DOX) to iron oxide nanoparticles that modified with folic acid. The results of MTT assay showed that the nanoparticles carrying Dox have faster and stronger impact on the growth inhibition of gastric cancer cells (AGS) than compared with Dox release form. Fluorescence microscopy studies confirmed the Presence of nanoparticles loaded with doxorubicin in cancer cells. It can be concluded from this study that the targeting transfer of Dox with iron oxide nanoparticles have an important role in enhancing the performance and cytotoxic activity of Dox and It can be found in the future that this nanodrug delivery systems can be optimized for use in clinical applications and effective treatment of cancer.
\end{abstract}

Keywords: Magnetic nanoparticles; Drug delivery; Doxorubicin; Cancer

\section{Introduction}

Doxorubicin (Doc) an anthracycline antibiotic classes and antineoplastic agent that is very effective for the treatment of various malignancies such as leukemia and ovarian cancer is routinely used especially in the advanced stages of breast cancer [1,2]. This compound is produced by Streptomyces Peucetius and a variety Cassius (Table 1) [3]. Due to the strong side-effects associated with the drug, especially damage to the heart and also with respect to the drug resistance of cancer cells, the circulatory system less stable, heterogeneous tumor tissue and the loss of influence of hard drugs into the body by degrading enzymes, applications clinical trials faced with restrictions $[4,5]$. Associationwith of Doxorubicin with drug carriers such as liposomes has been shown significantly reduced the effects of dose dependent -cardiac toxicity [6]. Research conducted show that superparamagnetic iron oxide nanoparticles with poly ethylene glycol: PEG have been covered and loaded with doxorubicin, have the distribution of the same size $(60 \mathrm{~nm})$ and zeta potential of zero at physiological $\mathrm{pH}$ that these two parameters suited the properties of nanoparticles to prevent the removal of colloidal nanoparticles by the immune system and increase the stability of nanoparticles in biological environments [7]. With targeting the drugs and direct delivery of anticancer drugs to the tumor sites and their accumulation in the tumor, you can prevent many of the unwanted side effects of the drugs and increase the their cytotoxic effects on the cancer cells [8]. With encapsulating of superparamagnetic iron oxide nanoparticles and doxorubicin within nano-micelles that their surface is decorated with folic acid molecules, the entry of nanoparticles into tumor cells in order to effective transfer of pharmacological agents and targeted MRI imaging, can be facilitated [9]. Many Principles and methods for targeting of drugs in to the tumor site have been evaluated. Among these methods, association of drug with superparamagnetic iron oxide nanoparticles (SPIONs) in magnetic drug targeting has been developed. These composite nanoparticles by using a magnetic field gradient that is focused on the tumor can be accumulate in tumor cells [10]. The superparamagnetic iron oxide nanoparticles loaded with Doc have several desirable properties that make them suitable in magnetic drug targeting Including that: (1) a high amount of drug can be loaded (2) Doc release of iron oxide nano-carrier to its original form and will be activated (3) release of Doc from its vehicle is depends on the $\mathrm{pH}$ and in values of acidic $\mathrm{pH}$ considerable release takes place So in considering the acidic $\mathrm{pH}$ around the tumor the release process will be conducted in the tumor that its $\mathrm{pH}$ is more acidic than blood flow. (4) Biological evaluation of nanoparticles loaded with doxorubicin proves that Dox drug cytotoxicity against cancer cells not only is maintained but also its activity in the special conditions is more severe compared to free Dox. These antineoplastic activity of Doc due to the drug loading is obtained $[4,10]$. Due to the high expression of folic acid receptors on the surface of cancer cells with targeting of magnetic iron oxide nanoparticles through the connection of folic acid to the surface of nanoparticles, It is expected that have the more efficient performance in transportation of Dox than In free-form of Dox to cancerous cells [11]. As a result, the toxic effect of DOC in the loaded form is greater than in free state, this effect is due to the rapid delivery of nanoparticles to cells occurs in less time [4]. Further studies suggest that folic acid

*Corresponding author: Mohammed Ghanbari, Department of Biology, Faculty of Science, University of Mohaghegh Ardabili, Ardabil, Iran, Tel: 09129242804; E-mail: mohamadghanbari60@yahoo.com

Received January 04, 2016; Accepted April 15, 2016; Published April 22, 2016

Citation: Ghanbari M, Asadi A, Rostamzadeh S (2016) Study of the Cytotoxicity Effect of Doxorubicin-loaded/Folic acid-Targeted Super Paramagnetic Iron Oxide Nanoparticles on AGS Cancer Cell Line. J Nanomed Nanotechnol 7: 368. doi:10.4172/2157-7439.1000368

Copyright: (c) 2016 Ghanbari M, et al. This is an open-access article distributed under the terms of the Creative Commons Attribution License, which permits unrestricted use, distribution, and reproduction in any medium, provided the original author and source are credited. 
receptor expressing tumor cells more than cells lacking the receptor absorbs a large amount of superparamagnetic iron oxide nanoparticles that modified with folic acid [12]. The results of the research conducted with Haider and colleagues in 2013 showed that the magnetic iron oxide nanoparticles modified with folic acid loads a high level of tamoxifen (49.1\%) and shows a high percent of release and sustained delivery (90\%) of tamoxifen molecules. The results of testing the cytotoxicity of nanoparticles as well as fluorescence microscopy and flow cytometry studies show that folic acid-modified and tamoxifen-loaded magnetic iron oxide nanoparticles, significantly interacted with MCF7 cancer cells (Because of overexpression of folate receptors on their surface) and effectively inhibited the growth of these cells [13]. This hypothesis can be considered that iron oxide nanoparticles have a synergistic effect when combined with DOX and shows stronger performance $[4,10]$. The aim of this study is to investigate the toxic effect of doxorubicin on AGS cancer cells in free mode and loaded on magnetite nanoparticles targeted with folic acid and compared them to be together.

\section{Materials and Methods}

The list of chemicals used to make nanoparticles of magnetite in Table 2 below. These materials from Merck (Merck KGaA) (a manufacturer of chemicals and pharmaceuticals company in Germany) and are of high purity, so that no purification of the reaction has not been renewed on raw materials.

\begin{tabular}{|l|l|}
\hline Name & Doxorubicin hydrochloride \\
\hline Brand name & Adriamycin \\
\hline Pharmaceutical Group & Antineoplstics \\
\hline gharmaceutical chemical & Glycoside antra cyclin \\
\hline Mechanism of action & $\begin{array}{l}\text { DNA-binding and inhibition of DNA and RNA } \\
\text { synthesis by disrupting the molecular structure and } \\
\text { obstruct space, Induction of apoptosis }\end{array}$ \\
\hline Indications & $\begin{array}{l}\text { Acute lymphocytic leukemia, acute myeloblastic } \\
\text { leukemia, testicular interstitial cell carcinoma, } \\
\text { ovarian, thyroid, Wilm's tumor, lungs (bronchial } \\
\text { origin), gastric, head and neck, liver, cervix, } \\
\text { prostate, endometrium, testis, lymphoma Hodgkin, } \\
\text { soft tissue sarcoma and bone sarcoma }\end{array}$ \\
\hline Intake & $\begin{array}{l}\text { Adults: 75-60 mg/m²/day- Administered } \\
\text { intravenously }\end{array}$ \\
\hline Indications & $\begin{array}{l}\text { Interference with concurrent use of allopurinol } \\
\text { and colchicine, Concurrent use with daunorubicin } \\
\text { increased risk of heart complications, Barbiturates, } \\
\text { increase hepatic metabolism and reduce plasma } \\
\text { drug levels, Streptozocin increase plasma levels } \\
\text { of the drug, increase the risk of skin complications } \\
\text { radiotherapy and intensity of hemorrhagic cystitis } \\
\text { caused by cyclophosphamide, Concomitant use } \\
\text { with other cytotoxic agents induced bone marrow } \\
\text { complications }\end{array}$ \\
\hline
\end{tabular}

Table 1: Information related to doxorubicin (Dox).

\begin{tabular}{|c|c|c|c|}
\hline$\%$ Purity & Material & $\%$ Purity & Material \\
\hline $99.50 \%$ & {$\left[\mathrm{FeCl}_{2} \cdot 4 \mathrm{H}_{2} \mathrm{O}\right]$} & $98 \%$ & {$\left[\mathrm{FeCl}_{3} \cdot 6 \mathrm{H}_{2} \mathrm{O}\right]$} \\
\hline $98 \%$ & $\begin{array}{c}\text { Dimethyl Sulphoxide } \\
(\mathrm{DMSO})\end{array}$ & $99 \%$ & $(25 \%) \mathrm{NH} 3$ \\
\hline $97 \%$ & $\mathrm{NaOH}(3 \mathrm{M})$ & $98 \%$ & $\begin{array}{c}\text { Tetraethyl orthosilicate } \\
(\mathrm{TEOS})\end{array}$ \\
\hline $97 \%$ & $\begin{array}{c}\text { Aminopropyl } \\
\text { trimethoxysilane (APTMS) }\end{array}$ & $99.90 \%$ & Ethanol $\left(\mathrm{C}_{2} \mathrm{H}_{5} \mathrm{OH}\right)$ \\
\hline $97 \%$ & $\left(\mathrm{C}_{6} \mathrm{H}_{8} \mathrm{O}_{7}\right)$ Citric acid & $99.99 \%$ & Folic acid (FA) \\
\hline $99.99 \%$ & $\begin{array}{c}\text { Doxorubicinhydrochloride } \\
(\text { DOX) }\end{array}$ & $95 \%$ & $\begin{array}{c}\mathrm{N}, \mathrm{N},- \\
\text { dicyclohexylcarboimide } \\
(\mathrm{DCC})\end{array}$ \\
\hline
\end{tabular}

Table 2: Chemicals used to make nanoparticles of magnetite.

\section{Uploading of doxorubicin (Dox) on the surface of folic acid- modified iron oxide nanoparticles and characterization of its physico-chemical properties}

In this research, the iron oxide nanoparticle (magnetite) was synthesized by Co-precipitation method and in order to increase stability and Prevent particle aggregation and clotting as well as providing reactive groups to connect of different molecular ligands to the surface of nanoparticle, its surface e was modified with silica (TEOS) and amines (APTMS) groups. In the next step reaction with binding of folic acid molecules to amino groups on the surface of nanoparticles, magnetic targeted nanoparticles were synthesized (Figure 1) [14,15]. At the end of the synthesis of nanoparticles, water-soluble anticancer drug (DOX) as a model of anticancer drug uploaded on the surface of folic acid-modified iron oxide nanoparticles by dissolving $5 \mathrm{mg}$ of it in $5 \mathrm{ml}$ aqueous solution of DOX (drug concentration $0.1 \mathrm{mg} / \mathrm{ml}$ ). A mixture of iron oxide nanoparticles in DOX with speed $200 \mathrm{rpm}$ in $37^{\circ} \mathrm{C}$ was stirred for 24 hours. Magnetic nanoparticles were removed from the solution and then drug-loaded magnetic nanoparticles was dried up. For the identification and characterization of the synthesized material, DRS (Diffuse Reflectance Spectroscopy) and FT-IR(Fourier Transform InfraRed) spectra of samples with devices Scinco S 4100 korea and RXI FT-IR 2400 Perkin-Elmer, using solid $\mathrm{KBr}$ tablets were recorded. The UV/vis Spectrum of samples was measured by Shimadzu UV 1700 spectrophotometer in solvents of distilled water and in $1 \mathrm{~cm}$ length quartz cells. X-ray diffraction patterns of the samples using PW 1800 PHILIPS and CuKa radiation was recorded. SEM (scanning electron microscope) images and elemental analysis (EDAX: Energy Dispersion X-ray spectroscopy) of the samples were obtained using the device LEO $1430 \mathrm{vp}$. VSM (Vibrating Sample Magnetometry) analysis of prepared samples was performed using the device (VSM Lecshore) at room temperature.

\section{Cell line}

Gastric cancer cell line (AGS) as a cancer cell model was purchased from Pasteur Institute of Iran. This cell line have a fibroblastic morphology and as a single layer attached to the bottom of plate and spread. Cells in culture medium of RPMI 1640, medium containing $10 \%$ fetal bovine serum and $2 \%$ penicillin-streptomycin antibiotic in the incubator with $5 \%$ carbon dioxide gas was reproduced and after three successful passage MTT assay on the Cell line was performed.

\section{Materials and equipments for cell culture and cytotoxicity assay}

Incubator, ELISA reader, laminar hood, inverted microscope (reverse phase) and a sampler in Different sizes (construction of Biotech company), flask 25 , shakers and cell culture plate 96 well, dimethyl sulfoxide (DMSO), MTT (3-(4,5-Dimethylthiazol-2-yl)-2,5-diphenyl Tetraziolium Bromide), Medium RPMI 1640, fetal bovine serum (Fetal Bovine Serum), a solution of Trypsin-EDTA, phosphate buffered saline (PBS), a solution of antibiotic penicillin $100 \mathrm{U} / \mathrm{ml}$-streptomycin 100 $\mu \mathrm{g} / \mathrm{ml}$ (Pen/Stp) from Sigma-Aldrich Germany (sigma-Aldrich).

Study the effect of cytotoxicity of folic acid-targeted/ doxorubicin-loaded iron oxide nanoparticles by MTT assay

To study the effect of cytotoxicity of free doxorubicin and folic acid-targeted and doxorubicin-loaded iron oxide nanoparticles, first AGS cells to 20 thousand cells per well in 96-well plates cultured and for 24 hours were incubated up to they reach early growth phase. After 24 hours, remove the supernatant then cells was treated with 

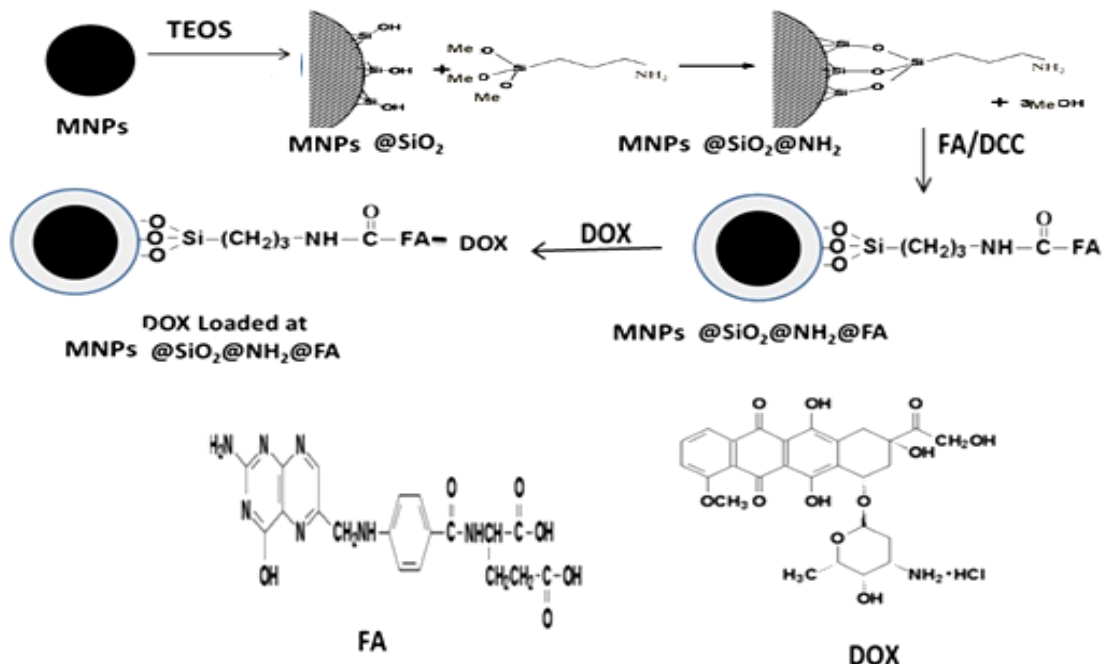

Figure 1: The formation mechanism of iron oxide nanoparticles(MNPs) coated with silica groups $\left(\mathrm{SiO}_{2}\right)$, amino propyl tri-methoxy-silane $\left(\mathrm{NH}_{2}\right)$, folic acid $(\mathrm{FA})$ and loaded with doxorubicin(Dox).

$200 \mu \mathrm{l}$ medium containing of nanoparticle compound and Dox at a concentration of $1,4,7.10$ and $15 \mathrm{mM}(\mathrm{M \mu})$ and at intervals of 4,24 and $48 \mathrm{~h}$. After a desired time, supernatant containing nanoparticles discarded and the bottom of each well (which cells that are attached it to) were washed 3 times with PBS. Then the MTT assay was used to determine the survival rate of the cells. In this way to each well 100 $\mu \mathrm{l}$ medium containing $10 \%$ solution of $0.5 \mathrm{mg} / \mathrm{mL}$ MTT was added. After 4 hours, the MTT solution was replaced by $200 \mu$ DMSO for dissolve the formazan crystals. After 15 minutes, the resulting solution absorption at a $540 \mathrm{~nm}$ wavelength with Elisa reader (Multi well plate reader) was measured. It should be noted that all the tests were done in three replicates. The Excel software was used to statistical analysis of data. The data was entered in Excel software and statistical analysis based on Descriptive statistics with a significance level of $95 \%$ was performed. Then a diagram of cell viability drawn and standard error of samples were entered in the diagram. The way of calculation the viability of treated cells as compared to control cells is through the following formula:

$\%$ viability $=($ Optical density of treated cells extract $) /($ Optical density of control cells extract )

\section{Study of cell morphology}

Reverse-phase microscopy was used for morphological studies of cells. At the first the cells was treated with nanoparticles in different concentrations and after the treatment time, the morphology of treated cells compared to control (untreated cells) under reverse phase microscope with a magnification $40 \mathrm{X}$ was investigated.

\section{Study the penetration of nanoparticles into the AGS cells} with fluorescence microscopy

Fluorescence microscopy in order to investigate the penetration of nanoparticles into the cells was used [16]. Due to the presence of aromatic rings in the structure of doxorubicin, this drug has internal fluorescent that excited at a wavelength $430 \mathrm{~nm}$ and shows light emission [4]. So be detected under a fluorescence microscope and of this feature was used for its entry into AGS cells. Because of folic acidtargeted magnetite nanoparticles loaded with doxorubicin in their surface so this method can be used to search for enter the nanoparticles to cells. This was the method by which first cells for 3 hours with free doxorubicin and doxorubicin-loaded nanoparticles were treated. Then the supernatant was removed and cells were washed 3 times with PBS so that there is no substance in the culture medium. Then the cells were washed with trypsin to detach from the bottom of plate. After the cells in $200 \mu \mathrm{l}$ PBS buffer suspended and a few drops of it was transferred to the neobar lam and examined by fluorescence microscopy.

\section{Results}

With doxorubicin loading on the surface of magnetic nanoparticles coated with silica and functionalized with amino propyl tri-methoxysilane and targeted with folic acid, the desired product was obtained. In order to identify obtained-products, the various analyzes were performed. Figure 1 tells the formation mechanism of desired products at every step:

FT-IR, DRS and UV /vis spectrum of doxorubicin (DOX) loaded on folic acid-modified magnetic nanoparticles (MNPs @SiO $\left.@ \mathrm{NH}_{2} @ \mathrm{FA} @ D o x\right)$

Figure $2 \mathrm{~A}(\mathrm{~b})$ shows the FT-IR spectra of resulting combination. In the spectrum of pure doxorubicin [Figure $2 \mathrm{~A}(\mathrm{a})$ ], couriers on 3382 $\mathrm{cm}-1$ due to $\mathrm{N}-\mathrm{H}$ stretching vibration for structure of primary amine, $2923 v(\mathrm{C}-\mathrm{H}), 1719 v(\mathrm{C}=\mathrm{O})$, bending $1516 v(\mathrm{~N}-\mathrm{H}), 1413 v(\mathrm{C}-\mathrm{C})$, $1288 v(\mathrm{C}-\mathrm{O}-\mathrm{C}), 1073 v(\mathrm{C}-\mathrm{O}), 891,782 v(\mathrm{~N}-\mathrm{H})$ indicates. But when DOX loaded on the folic acid-modified nanoparticles, the $\mathrm{C}=\mathrm{O}$ peaks which had appeared in the spectrum of pure DOX was deleted. Of the results of FT-IR can be concluded that connection of DOX to the magnetite nanoparticles modified with folic acid, it happens by the interaction of $\mathrm{COOH}$ groups of DOX with $\mathrm{NH} 2$ groups of folic acid. The study of DRS spectrum of nanoparticles loaded with doxorubicin (Figure 2B), shows the presence of two peaks at $250 \mathrm{~nm}$ and $360 \mathrm{~nm}$, that are respectively related to magnetite nanoparticles $\left(\mathrm{Fe}_{3} \mathrm{O}_{4}\right)$ and doxorubicin molecule [17]. In general, the results of the studies of FTIR and DRS of samples, confirmed successful loading of doxorubicin on magnetite nanoparticles modified with folic acid.

UV-vis spectrum of folic acid have a strong peak at $283 \mathrm{~nm}$ that slightly does shift from $283 \mathrm{~nm}$ to $295 \mathrm{~nm}$, after the connecting of FA to magnetite nanoparticles coated with silica and functionalized with amino propyl tri methoxy silane $\left(\mathrm{Fe}_{3} \mathrm{O}_{4} @ \mathrm{TEOS} @\right.$ APTMS) (Figure 

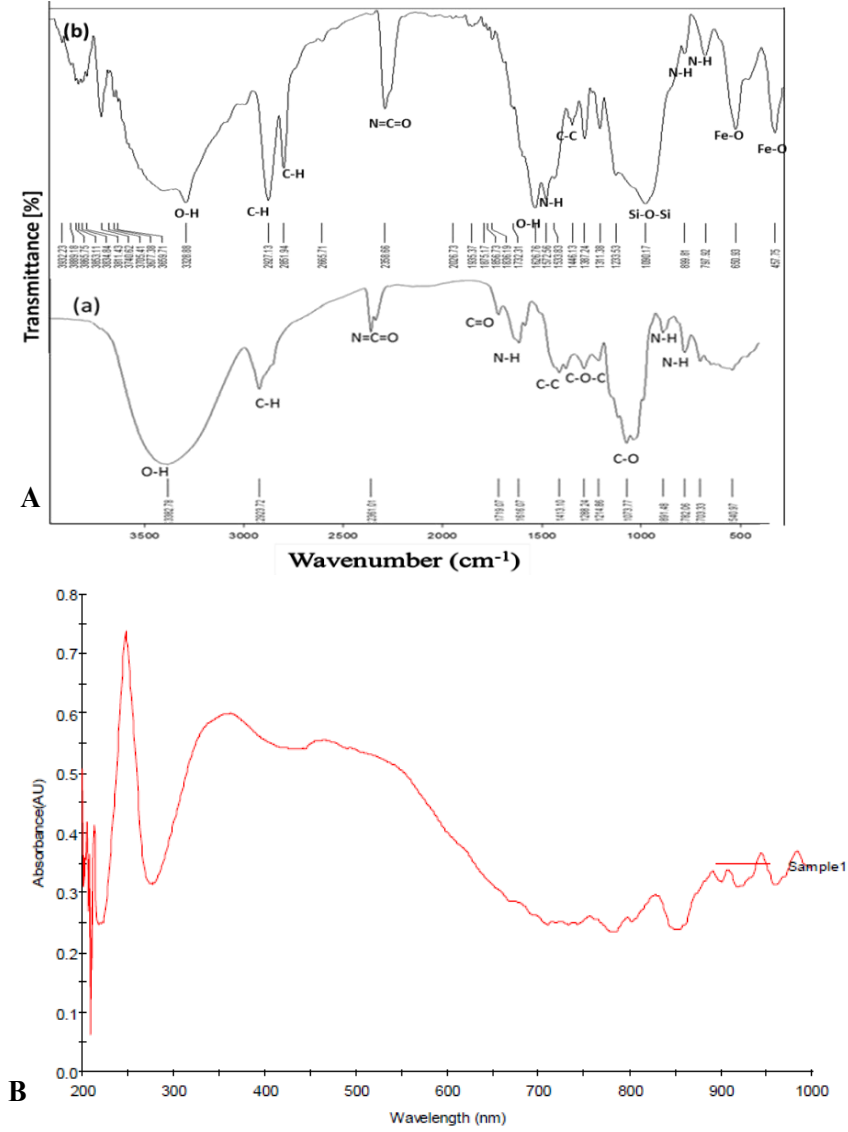

Figure 2: A: The FT-IR Spectrum of (a) doxorubicin (b) doxorubicin loaded into the magnetite nanoparticles coated with silica, functionalized with amino propyl tri methoxy silane and congugated with folic acid. B: the DRS spectrum of magnetite nanoparticles modified with folic acid and loaded with doxorubicin.

3a). After the loading of DOX on nanoparticles, the peaks at $234 \mathrm{~nm}$ and $482 \mathrm{~nm}$, because of the loading of DOX, in the UV-vis spectrum can be seen (Figure $3 \mathrm{~b}$ ) which a bit does shift from absorption peaks of free DOX at $233 \mathrm{~nm}$ and $481 \mathrm{~nm}$. Small shifts may caused from the interaction of loaded DOX with conjugated FA. All of these results suggest that loading of DOX on the nanoparticles has been successful [18].

Study of SEM of magnetite nanoparticles $\left(\mathrm{Fe}_{3} \mathrm{O}_{4}\right)$ and its modified forms with silica, amines, folic acid and loaded with doxorubicin

To study the morphology and surface structure of nanoparticles obtained, Scanning Electron Microscope (SEM) images were also evaluated. The images of SEM taken from the nanoparticles shows that the shape of nanoparticles has been the same size, uniform and spherical. And coating the nanoparticles with silica, amino and folic acid and its loading with doxorubicin did not cause much change in morphological characters of nanoparticles. Yang and colleagues from the electron microscopy images found that magnetic nanoparticles carrying Dox and coupled with folic acid has a uniform and spherical shape and with diameter of $180 \mathrm{~nm}$ have been synthesized. Elemental analysis data (EDAX) are given for sample of magnetite nanoparticles $\left(\mathrm{Fe}_{3} \mathrm{O}_{4}\right)$ in Table 2. EDAX spectra shows the presence of $\mathrm{Fe}, \mathrm{O}$ (Figure 4).

\section{Study the magnetic properties of magnetite nanoparticles}

Figure $5 \mathrm{a}, 5 \mathrm{~b}$ and Table 3 , shows the parameters magnetization related to the magnetic field, $\mathrm{M}(\mathrm{H})$ (magnetic field with intensity $\mathrm{H}$ ) for the $\mathrm{Fe}_{3} \mathrm{O}_{4}$ and $\mathrm{Fe}_{3} \mathrm{O}_{4} / \mathrm{SiO}_{2}$ using vibrating sample magnetometer(VSM) at room temperature in field of $15 \mathrm{KOe}$ (Oe: Orsted, the unit of magnetic field in the system cgs). The superparamagnetic behavior of magnetite nanoparticles $\left(\mathrm{Fe}_{3} \mathrm{O}_{4}\right)$ is confirmed by the absence of hysteresis loop in magnetization curve of this compound. The saturation magnetization (Ms) of this compound $\left(\mathrm{Fe}_{3} \mathrm{O}_{4}\right)[60 \mathrm{emu} / \mathrm{g}]$ with the coercivity value $(\mathrm{Hc}=0.0 \mathrm{Oe})$ and magnetic remanence $(\mathrm{Mr}=0.0 \mathrm{emu} / \mathrm{g})$ at a temperature of $300^{\circ} \mathrm{k}$ shows the superparamagnetic behavior of the magnetite nanoparticles. The review of the VSM curve of magnetite nanoparticles coated with silica indicated that,due to the absence of hysteresis loop, they have the superparamagnetic properties. But the saturation magnetization of this combination $\left(\mathrm{Fe}_{3} \mathrm{O}_{4} / \mathrm{SiO}_{2}\right)$ is $35 \mathrm{emu} / \mathrm{g}$ (Electro-magnetic unit) that represent a reduction of magnetism as a result is covered with silica, which due to the locating of covering groups around the substrate of magnetite than the initial magnetite, is reduced. In general, this test shows that coating the surface of iron oxide nanoparticles, does not remove the superparamagnetic property from them. Iron oxide nanoparticles smaller than $20 \mathrm{~nm}$ often at room temperature shows superparamagnetic property of their. The magnetite nanoparticles $\left(\mathrm{Fe}_{3} \mathrm{O}_{4}\right)$ smaller than $6 \mathrm{~nm}$ at room temperature have the superparamagnetic behavior, but in general, the magnetic properties of these particles are dependent on the method of preparation them. Rana and his colleagues have reported that the magnetic properties of magnetite nanoparticles depends on a lot to change in crystal morphology [19].

The results of MTT assay to examine the cytotoxicity of doxorubicin and magnetite nanoparticles targeted with folic acid and loaded with doxorubicin on viability of AGS cell line and evaluation of morphological changes of cells

AGS cells with doxorubicin-loaded nanoparticles and free doxorubicin at concentrations that are equal to each other in three different interval 4, 24 and $48 \mathrm{~h}$ were treated and then MTT assay to assess the survival fraction of treated cells compared to control cell

\begin{tabular}{|c|c|c|}
\hline Samples & Ms (emu/g) & Hc (Oe) \\
\hline $\mathrm{Fe}_{3} \mathrm{O}_{4}$ & $60 \mathrm{emu} / \mathrm{g}$ & 0 \\
\hline $\mathrm{Fe}_{3} \mathrm{O}_{4} / \mathrm{SiO}_{2}$ nanoparticles & $35 \mathrm{emu} / \mathrm{g}$ & 0 \\
\hline
\end{tabular}

Table 3: Magnetic parameters of nanoparticles of $\mathrm{Fe}_{3} \mathrm{O}_{4}$ and $\mathrm{Fe}_{3} \mathrm{O}_{4} / \mathrm{SiO}_{2}$.

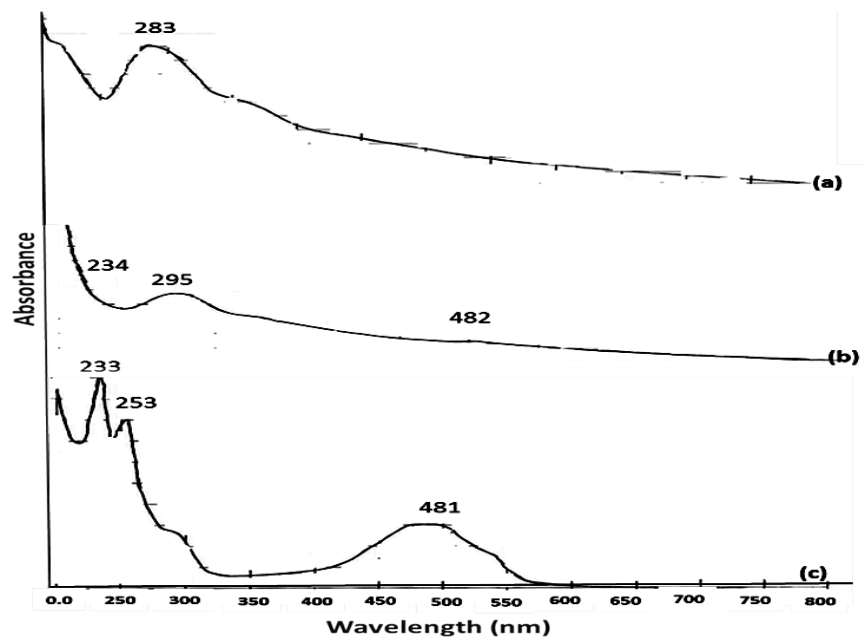

Figure 3: The spectrum of UV-vis of (a) folic acid (b) doxorubicin loaded on the magnetite nanoparticles coated with silica, functionalized with amino propyl tri methoxy silane and conjugated with folic acid (c) doxorubicin molecule. 
Citation: Ghanbari M, Asadi A, Rostamzadeh S (2016) Study of the Cytotoxicity Effect of Doxorubicin-loaded/Folic acid-Targeted Super Paramagnetic Iron Oxide Nanoparticles on AGS Cancer Cell Line. J Nanomed Nanotechnol 7: 368. doi:10.4172/2157-7439.1000368

(a)

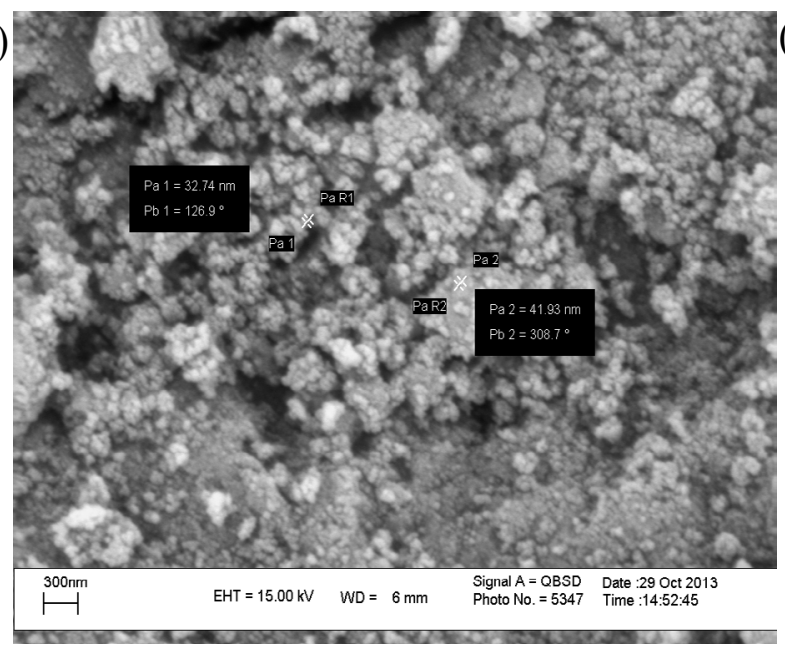

(c)

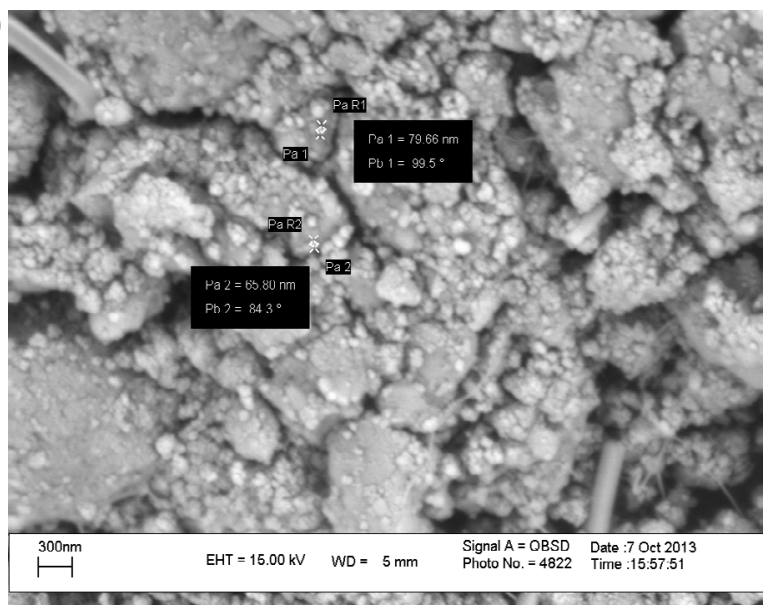

(b)

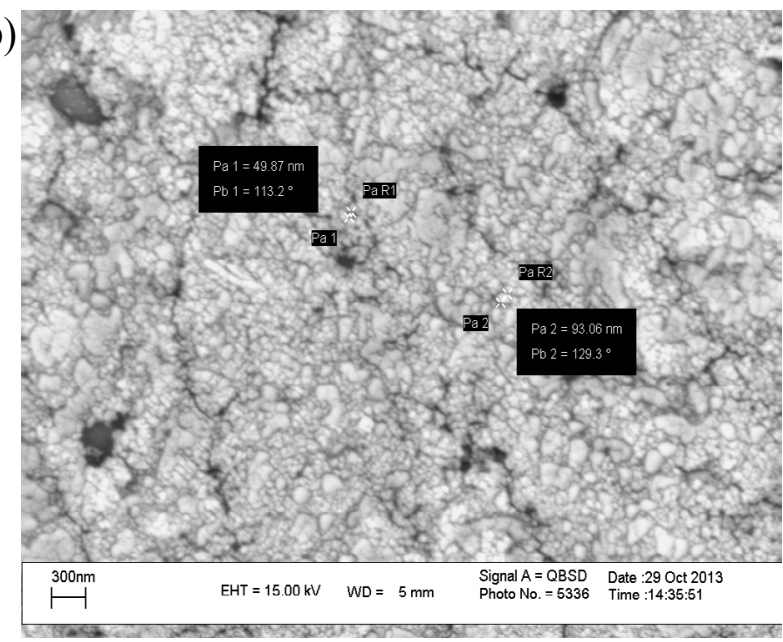

(d)

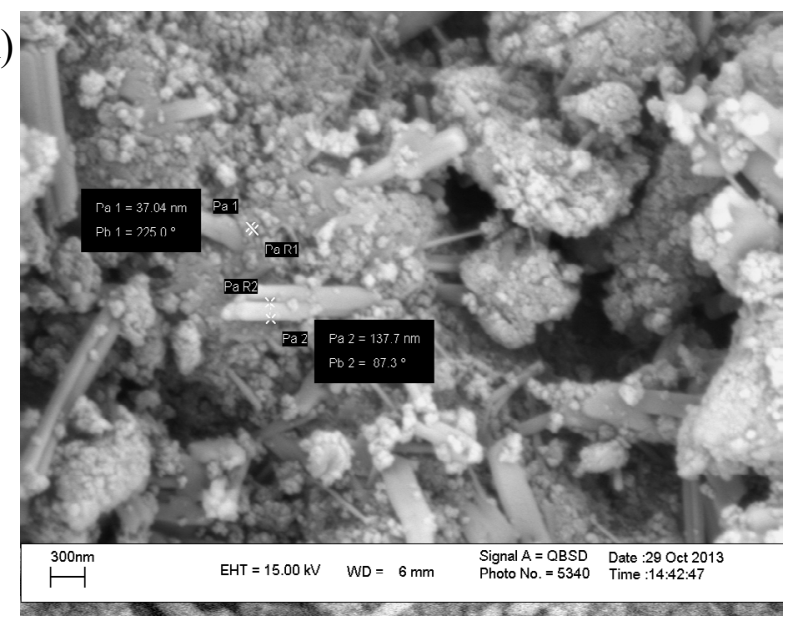

Figure 4: SEM images of: a) magnetite nanoparticles b) magnetite nanoparticles coated with silica and functionalized with amine c) magnetite nanoparticles coated with silica, functionalized with amine and targeted with folic acid d) magnetite nanoparticles coated with silica, functionalized with amine, targeted with folic acid and loaded with doxorubicin, morphological shapes of nanoparticles confirms the spherical and uniform shape and size of synthesized nanoparticles.
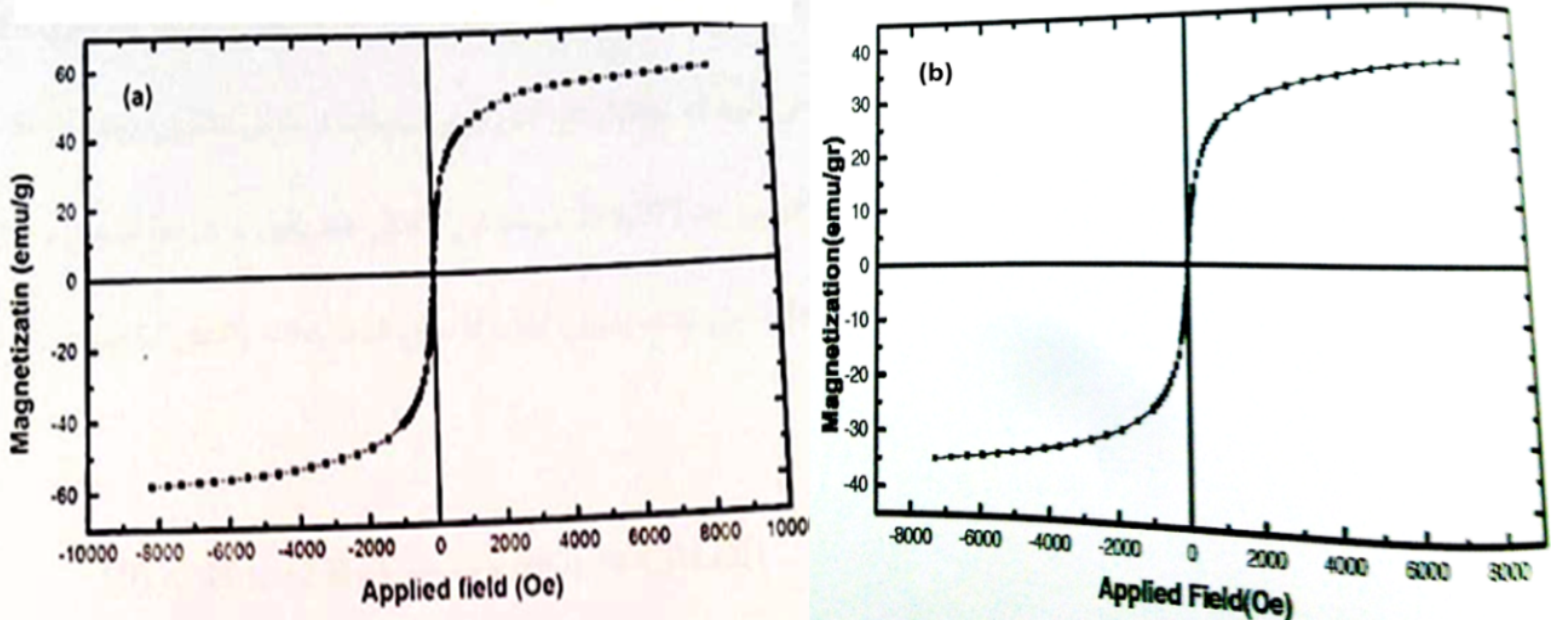

Figure 5: The magnetization curve in terms of the field, nanoparticles of (a) $\mathrm{Fe}_{3} \mathrm{O}_{4}$ and (b) $\mathrm{Fe}_{3} \mathrm{O}_{4} / \mathrm{SiO}_{2}$, this study shows that magnetic iron oxide nanoparticles have superparamagnetic property and despite the coating nanoparticles with a layer of silica $\left(\mathrm{SiO}_{2}\right)$ the superparamagnetic property has been preserved. 
survival fraction was performed. The results of MTT assay in Figures 6-8 are shown. In these figures, percentage of viability of cells in both modes of treated with doxorubicin-loaded nanoparticles and free doxorubicin has been investigated. Figure 6 shows that with increasing concentrations of doxorubicin-loaded nanoparticles (Dox$\mathrm{FA} / \mathrm{MNP}$ ) from 0 to $4 \mu \mathrm{M}$, the cell viability is gradually reduced. This reduction in viability of cells shows a statistically significant difference in compared to control group (cells treated with free doxorubicin). And in concentration of 4 to 15 the significant increase in inhibition of cell growth cannot be seen. In this graph, it can be concluded that the inhibitory effect of DOX-loaded nanoparticles in the treatment for 4 hours to a certain extent is proportional to the concentration. And with increasing concentration of nanoparticle to 4 micromolar, cell growth was stopped And beyond of this amount the cells shows resistance to the medication. In contrast, free doxorubicin (DOC) in the early stages of treatment (4 hours) does not affect the viability of AGS cells (Figure 6). It seems that in the long term, DOX is effective on cell growth. Figure 6 approved the high toxicity of DOX-loaded nanoparticles with in accordance with the concentration, whereas free DOX does not show toxicity at this time (4 hours). The results show that IC50 values for loaded DOX in each time interval is less than free doxorubicin IC50. Especially in the treatment of 4 hours as this parameter in this treatment for DOX-loaded nanoparticles, $3.65 \mu \mathrm{M}$ and free DOX,53.26 $\mu \mathrm{M}$ were obtained, that the difference between these two is enormous, (Table 4). The results of treatment of 24 hours of AGS cells with nanoparticles of magnetite targeted with folic acid (FA) and loaded with DOX (Dox-FAMNP), in Diagram Figure 7 shows that the percentage viability of cells at all concentrations of treatment have a large difference with together. And the range of standard error of the samples in all treatment concentrations are overlap and statistically significant difference in the viability of treated cells compared to control cell survival fraction (concentration of zero) was not observed. In treatment of 24 hours (Figure 7) the viability of cells at concentration of $1 \mu \mathrm{M}, 37.93 \%$ and in concentration of $15 \mu \mathrm{M}, 21.37 \%$ was abtained respectively. These results shows that the doxorubicin-loaded nanoparticles needs more time to be applying their function on the inhibition of cell grow. The results of the treatment of cells in 24 hours

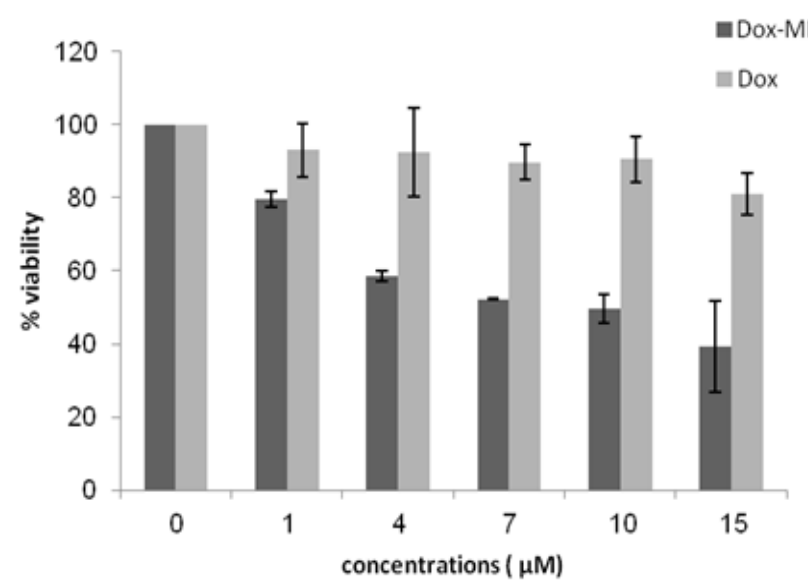

Figure 6: Column chart of percent of viability of AGS cells after 4-hour treatment with free doxorubicin (Dox) and magnetic nanoparticles targeted with folic acid and loaded with doxorubicin (Dox-MNPFA). Comparison of the viability of AGS cells in both treatments with Dox-loaded nanoparticles and free Dox, shows that Dox have a stronger and significant effect on inhibiting cell growth in loaded form on magnetic nanoparticle than the free form of the drug ( $P$-value $\leq 0.15)$. This chart shows the effective role of nanoparticles in strengthening the function and inhibition of Dox in cell growth.

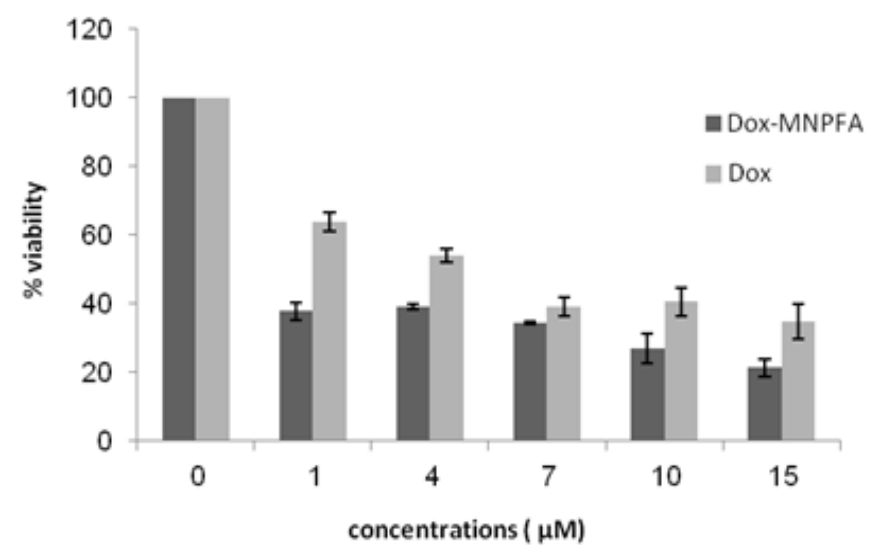

Figure 7: Column chart of percent of viability of AGS cells after 24-hour treatment with free doxorubicin (Dox) and magnetic nanoparticles targeted with folic acid and loaded with doxorubicin (Dox-MNPFA). This graph is confirmed the stronger effect of Dox-loaded nanoparticles than compared to free form of Dox on inhibition of cell growth. Percents of viability of cells in two modes of treated with Dox-loaded nanoparticles and free doxorubicin, shows a statistically significant difference at a significance level of $95 \%$.

\begin{tabular}{|c|c|c|}
\hline $\begin{array}{c}\text { Substance } \\
\text { Treatment time }\end{array}$ & Dox & Dox-MNPFA \\
\hline $4 \mathrm{~h}$ & $3.65 \mu \mathrm{M}$ & $53.26 \mu \mathrm{M}$ \\
\hline $24 \mathrm{~h}$ & $6.68 \mu \mathrm{M}$ & $2.86 \mu \mathrm{M}$ \\
\hline $48 \mathrm{~h}$ & $2.79 \mu \mathrm{M}$ & $2.16 \mu \mathrm{M}$ \\
\hline
\end{tabular}

Table 4: comparison of IC50 of doxorubicin in free mode and loaded onto iron oxide nanoparticles in timescales of 4,24 and 48 hours.

with free doxorubicin (Figure 7) show that in concentrations of 1 and 4 micromolar the percent of viability of cells, respectively, from $63.94 \%$ to $54.01 \%$ has decreased but at concentrations of 7,10 and $15 \mu \mathrm{M}$. The percent of cell viability $39.15 \%, 40.57 \%$ and $34.98 \%$, was obtained respectively, which does not show a statistically significant difference. The IC50 value for free doxorubicin in the treatment of 24 hours 6.68 $\mu \mathrm{M}$ is calculated. This graph showed that AGS cells indicate resistance to increasing concentrations of doxorubicin. Treatment of cells for 48 hours (Figure 8) shows the stronger influence of doxorubicinloaded nanoparticle (Dox-FAMNP) on inhibition of AGS cell growth compared to controls (free doxorubicin). Percent of viability of cells in concentrations of $1 \mu \mathrm{M}, 15 \mu \mathrm{M}$, respectively are, $17.89 \%$ and $10.49 \%$. This graph shows the effect of doxorubicin-loaded nanoparticles on the viability of AGS cells at all levels is the same, and percent of viability of cells have not statistically significant differences. This graph represents the effectless of concentration and the effectiveness of time on the performance of DOX-loaded nanoparticles on inhibition of cell growth, ie, with increasing treatment time, effect of concentration be decreased and more, a time indicate its effect. Results of 48-hour treated AGS cells with free doxorubicin (DOX), were as the results of treatment was 24 hours. According to Figure 8, the percent of cell viability in concentration of $1 \mu \mathrm{M}$ is $43.17 \%$ and in concentrations of 4 , 7,10 and $15 \mu \mathrm{M}$, respectively is, $12.85 \%, 12.38 \%, 19.79 \%, 12.23 \%$. Again in this case, a significant difference in the percentage of live cells at concentrations of 4 to $15 \mu \mathrm{M}$ (micromolar) is not observed. The graph shows that with increasing concentration of DOX from 0 to $4 \mu \mathrm{M}$, the percent of cell viability significantly decreased. And from 4 to $15 \mu \mathrm{M}$ percentages are not significantly different with each other, it seems that with increasing duration of treatment, DOX applies stronger effect on inhibiting cell growth. 


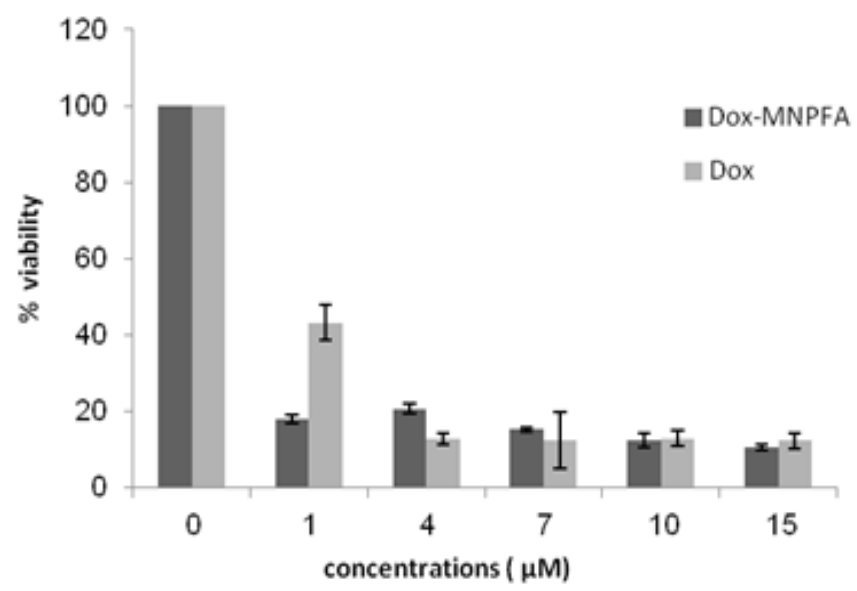

Figure 8: Column chart of percent of viability of AGS cells after 48-hour treatment with free doxorubicin (Dox) and magnetic nanoparticles targeted with folic acid and loaded with doxorubicin (Dox-MNPFA). In this range of time both compounds have almost the same toxicity on growth inhibition of cells. Comparison of cell viability in two modes that treated with free Dox and Doxcarrying nanoparticles showed that at concentrations of 1 and $4 \mu \mathrm{M}$, inhibitory effect of this two compounds is significantly different. But in concentrations of 7 to $15 \mu \mathrm{M}$, a significant difference in the survival rate of the AGS cells cannot be seen between these two compounds.

\section{Study the entry of doxorubicin to AGS cells in free mode and loaded on iron oxide nanoparticles with fluorescence microscopy}

Due to the inherent fluorescence quenching of Dox, entry of this drug into the cells can be examined by fluorescence microscopy and according to doxorubicin binding to the nanoparticles, the absorption of doxorubicin-loaded nanoparticles in AGS cells also can be studied with this method. The results of studies of fluorescence microscopy approved the entry of doxorubicin and doxorubicin-carrier nanoparticles to AGS cells. Cells under the microscope as round and bright can be seen (Figure 9). This study is just confirmed the entry of doxorubicin to cells in both free and loaded onto the nanoparticle. From this image, it can be concluded that the nanoparticles are also entered to AGS cells. In fact, in this figure, the entery of folic acidtargeted iron oxide nanoparticles and Dox to AGS cells is confirmed.

\section{Discussion}

This study shows that synthesized iron oxide nanoparticles have a suitable physicochemical properties for biomedical applications. Magnetite nanoparticles (MNP) have not a toxic effect on viability of AGS cells and coating the nanoparticles (MNP) with silica (TEOS), amino propyl tri methoxy silane (APTMS) and folic acid (FA) can reduce the accumulation or aggregation of nanoparticles and also provides capable loading of doxorubicin and targeted delivery of Dox molecules to the AGS cells. The targeted delivery of Dox with targeted nanoparticles of iron oxide had an important role in strengthening the performance and cytotoxicity of this anticancer drug (Dox). Coating of magnetic iron oxide nanoparticles with biocompatible groups and appropriate molecular ligands, have a very important role in biomedical applications of nanoparticles. Because these nanoparticles have to transferred to target tissues that are tumor tissue and tumor cells and also have a long shelf life in the circulatory system so they can deliver pharmacologic agents to tumor cells. The results of recent research that has been done in this area indicates that the iron oxide magnetic nanoparticles that targeted with specific molecular ligands such as lactoferrin or ceruloplasmin cannot be phagocytosis or swallowed by skin fibroblasts. And the nano-particles that their superficial coverage are different, creates different cellular responses that are a result of the entry path and intracellular interactions of different nanoparticles that are coated with different molecules [20]. So coating the nanoparticles with molecular ligands plays an important role in the stability of nanoparticles in the body (not eliminated by the immune system) and in directing nanoparticles to the target tissue and in creation of suitable cellular responses. The results of this study shows that the magnetic iron oxide nanoparticles with silica, amino and folic acid groups, have been modified, indicates high colloidal stability and a high degree of dispersion in aqueous solutions than unmodified iron oxide nanoparticles. However, significant changes in biocompatibility, superparamagnetic properties and morphology of nanoparticles was not found. Surface coating also is created favorable biomedical properties and stability for this particles and is prevented from toxicity of magnetic nanoparticles due to their interaction with biological proteins or cells [21]. Superparamagnetic characteristic of magnetite nanoparticles is the origin of many of the unique properties of nanoparticles for their applications in the biomedical field. But more research is needed to investigate the mechanism of entry and intracellular interactions of folic acid-modified nanoparticles up to can use enforce more measures to optimize these nanoparticles and their entry into the clinical phases. In the present study to assess the cytotoxicity of synthesized nanoparticles the MTT assay was used. This method is very sensitive and precise so that the smallest changes in viability of cells can be revealed. In this study the cytotoxic effect of doxorubicin in a free state and loaded on folic acid-targeted iron oxide nanoparticles was examined by MTT assay. The results showed that in the 4-hour treatment, Dox-loaded nanoparticles have more effective activity on inhibition of growth of AGS cells than free Dox, while this difference in treatments of 24 and 48 hours less to be seen. In treatments of 24 and 48 hours, the Dox-loaded nanoparticles at low concentrations, showed stronger cytotoxicity than to single Dox while in higher concentrations of 7,10 and $15 \mu \mathrm{M}$, the cytotoxicity was approximately equal together. Of morphological and microscopic images of cells can be determined that the cells might be afoul with a apoptosis that this process takes place through mechanisms such as the induction of ROS production by iron oxide nanoparticles $[4,22]$. The results of Munnier and colleagues in 2008 and 2011 also demonstrate that 24-hour treatment of cells with Dox-SPION combination only if can be more active than free Dox that the applied-concentrations are below the IC50 values of above compounds. The results of this study were consistent with the findings of Munnier and colleagues in 2008. They examined the cytotoxicity of Dox at the same concentration in free mode and loaded on superparamagnetic iron oxide nanoparticles on MCF7 cells. The IC50 values in the treatment of 24 hours for Dox in a free state and loaded onto the SPION nanoparticles were found respectively 1.2 and $0.7 \mu \mathrm{M}$ [10]. According to the results of MTT assay obtained from 4-hour treatment of AGS cells with free Dox and Dox-loaded nano particles that were found percent viability of cells in a state of treated with Dox-loaded nanoparticles was decreased but remained unchanged in the treatment with free Dox, It can be assumed that the arrival of these two compounds to cells are different. Probably Dox-loaded nanoparticles via endocytosis path that is quick track was entered to the cell that is why they show its effectiveness quickly $[4,23]$. The results of this study shows that the impact of nanoparticles loaded with doxorubicin on cell viability was not dependent on the concentration and concentration to a certain extent is affected on the viability of cells. The main factor that affects the toxicity is the "time". 
Citation: Ghanbari M, Asadi A, Rostamzadeh S (2016) Study of the Cytotoxicity Effect of Doxorubicin-loaded/Folic acid-Targeted Super Paramagnetic Iron Oxide Nanoparticles on AGS Cancer Cell Line. J Nanomed Nanotechnol 7: 368. doi:10.4172/2157-7439.1000368

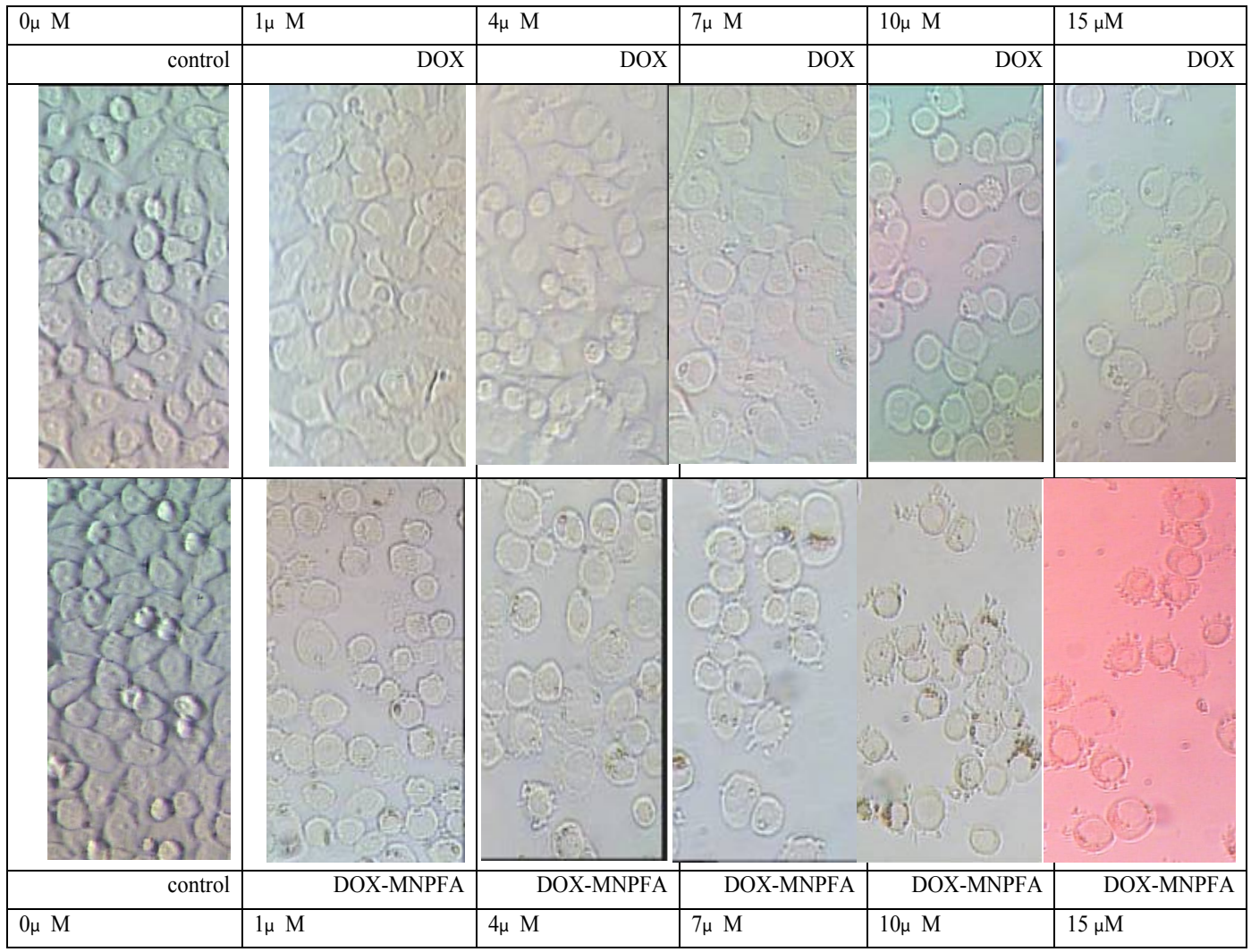
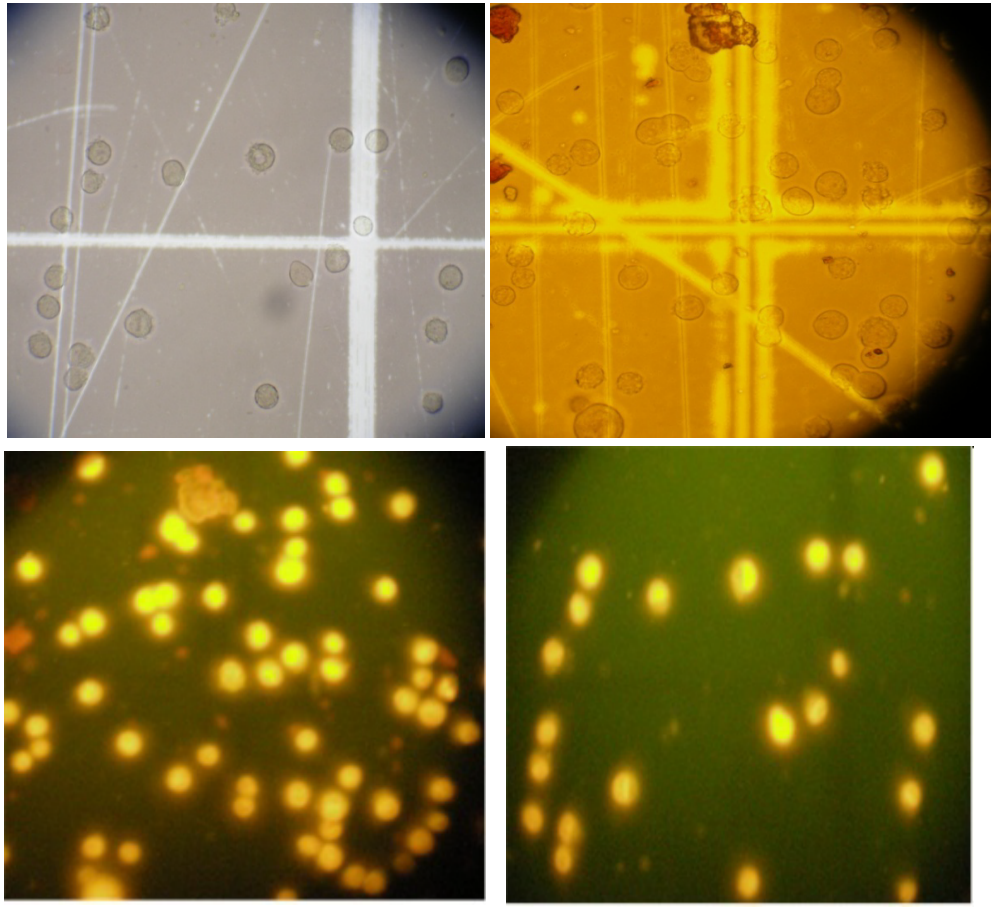

AGS cells treated with free doxorubicin AGS cells treated with doxorubicin-loaded nanoparticles

Figure 9: Fluorescence microscopy images of AGS cells treated with free doxorubicin and doxorubicin loaded nanoparticles, this image is confirmed the entry of doxorubicin-carrying nanoparticles and doxorubicin into AGS cells. Top images shows the shape of cells below the visible filter and the bottom images shows the shape of same cells under UV filters. Due to the characteristics intrinsic fluorescence of Dox in the ultraviolet region (wavelength $430 \mathrm{~nm}$ ) and fluorescence emission under the UV filter, the AGS cells are seen as bright. In both cases, the cell shows the similar fluorescence intensity. It shows that probably a part of Dox molecules after entering to the cell have been separated from its carrier and this release, due to the acidic $\mathrm{PH}$ of endosomes that swallowed by cells been done. And this phenomenon may be is the reason for the entry of nanoparticles into AGS cells via endocytosis. (Images taken with $40 \mathrm{X}$ magnification). 
Citation: Ghanbari M, Asadi A, Rostamzadeh S (2016) Study of the Cytotoxicity Effect of Doxorubicin-loaded/Folic acid-Targeted Super Paramagnetic Iron Oxide Nanoparticles on AGS Cancer Cell Line. J Nanomed Nanotechnol 7: 368. doi:10.4172/2157-7439.1000368

Page 9 of 9

In the early stages of treatment $(4 \mathrm{~h})$ the impact of the concentration on the inhibition of cell growth is more indicated (Figure 6). But over time, the impact of the concentration on the inhibition of cell growth have faded and the "time" more shows its effect so that it is evident in the treatment of 48 hours (Figure 8). Doxorubicin-loaded nanoparticles for the effective performance requires more time and this effect is stronger at higher concentrations. In general we can say that the viability of the cells in the early stages of treatment, is dependent on the concentration and in the long term is dependent on time. The results of this study demonstrate that by increasing the drug concentration and treatment time, more of cells inhibited and a small percentage of cells shows resistance to drug (Dox). This study and previous observations demonstrate that doxorubicin in the both free and loaded on iron oxide nanoparticles, have not linear behavior on inhibition of growth of AGS cells. This means that its performance is dependent on the concentration and the time factor have an important role in the development of performance of doxorubicin. It is likely that the distribution and intracellular interactions of Dox in a free mode and loaded on nanoparticles is different and the nanoparticles that loaded with Dox by strengthening the production of ROS (Reactive oxygen species) or other unknown mechanisms have an important role in creating high cytotoxicity [24,25].

\section{Conclusion}

This study demonstrates that targeting of iron oxide nanoparticles (magnetite) with folic acid molecules, which absorb and store the doxorubicin (Dox) on nanoparticles, also improves the transmission rate of nanoparticles to AGS cancer cells. Magnetic iron oxide nanoparticles itself have not toxic effect on AGS cells but in loaded with doxorubicin, induces higher rates of cell death in compared to free doxorubicin. As a result, these nanoparticles can be used to improve the effectiveness and reduce the side effects of the drug after completion of the tests in living environment.

\section{Acknowledgements}

This article is derived from the master thesis of Mr. Mohammed Ghanbari, therefore hereby authors, express gratitude and appreciation from the Research Center of university of mohaghegh ardabili due to their financial support from this project.

\section{References}

1. Bronchud MH, Howell A, Crowther D, Hopwood P, Souza L, et al. (1989) The use of granulocyte colony-stimulating factor to increase the intensity of treatment with doxorubicin in patients with advanced breast and ovarian cancer. British journal of cancer 60: 121-125.

2. Perez EA, Suman VJ, Davidson NE, Sledge GW, Kaufman PA, et al. (2008) Cardiac safety analysis of doxorubicin and cyclophosphamide followed by paclitaxel with or without trastuzumab in the North Central Cancer Treatment Group N9831 adjuvant breast cancer trial. J Clin Oncol 26: 1231-1238.

3. Hutchinson CR, Colombo AL (1999) Genetic engineering of doxorubicin production in Streptomyces peucetius: a review. Journal of industrial microbiology and biotechnology 23: 647-652.

4. Munnier E, Cohen-Jonathan S, Herve K, Linassier C, Souce M, et al. (2011) Doxorubicin delivered to MCF-7 cancer cells by superparamagnetic iron oxide nanoparticles: effects on subcellular distribution and cytotoxicity. Journal of Nanoparticle Research 13: 959-971.

5. O'brien MER, Wigler N, Inbar M, Rosso R, Grischke E, et al. (2004) Reduced cardiotoxicity and comparable efficacy in a phase III trial of pegylated liposomal doxorubicin $\mathrm{HCl}$ (CAELYX ${ }^{\mathrm{TM}} / \mathrm{Doxi}{ }^{\circledR}$ ) versus conventional doxorubicin for firstline treatment of metastatic breast cancer. Annals of oncology 15: 440-449.

6. Leonard RCF, Williams S, Tulpule A, Levine AM, Oliveros S (2009) Improving the therapeutic index of anthracycline chemotherapy: Focus on liposomal doxorubicin (Myocet). The Breast 18: 218-224.
7. Gautier J, Munnier E, Paillard A, Hervé K, Douziech-Eyrolles L, et al. (2012) A pharmaceutical study of doxorubicin-loaded PEGylated nanoparticles for magnetic drug targeting. International journal of pharmaceutics 423: 16-25.

8. Kubo T, Sugita T, Shimose S, Nitta Y, Ikuta Y, et al. (2000) Targeted delivery of anticancer drugs with intravenously administered magnetic liposomes in osteosarcoma-bearing hamsters. International journal of oncology 17: 309-324.

9. Li X, Li H, Yi W, Chen J, Liang B (2013) Acid-triggered core cross-linked nanomicelles for targeted drug delivery and magnetic resonance imaging in liver cancer cells. International journal of nanomedicine 8: 3019.

10. Munnier E, Cohen-Jonathan S, Linassier C, Douziech-Eyrolles L, Marchais $\mathrm{H}$ et al. (2008) Novel method of doxorubicin-SPION reversible association for magnetic drug targeting. International journal of pharmaceutics 363: 170-176.

11. Veiseh O, Gunn JW, Zhang M (2010) Design and fabrication of magnetic nanoparticles for targeted drug delivery and imaging. Adv Drug Deliv Rev 62: 284-304.

12. Kumar M, Singh G, Arora V, Mewar S, Sharma U, et al. (2012) Cellular interaction of folic acid conjugated superparamagnetic iron oxide nanoparticles and its use as contrast agent for targeted magnetic imaging of tumor cells. Int J Nanomedicine 7: 3503-3516.

13. Majd MH, Asgari D, Barar J, Valizadeh H, Kafil V, et al. (2013) Tamoxifen loaded folic acid armed PEGylated magnetic nanoparticles for targeted imaging and therapy of cancer. Colloids and Surfaces B: Biointerfaces 106: 117-125.

14. Sun C, Sze R, Zhang M (2006) Folic acid-PEG conjugated superparamagnetic nanoparticles for targeted cellular uptake and detection by MRI. Journal of Biomedical Materials Research Part A 78: 550-557.

15. Zhang JL, Srivastava RS, Misra RDK (2007) Core-shell magnetite nanoparticles surface encapsulated with smart stimuli-responsive polymer: synthesis, characterization, and LCST of viable drug-targeting delivery system. Langmuir 23: 6342-6351.

16. Tsien RY, Rink TJ, Poenie M (1985) Measurement of cytosolic free $\mathrm{Ca}^{2+}$ in individual small cells using fluorescence microscopy with dual excitation wavelengths. Cell calcium 6: 145-157.

17. Nawara K, Romiszewski J, Kijewska K, Szczytko J, Twardowski A, et al. (2012) Adsorption of doxorubicin onto citrate-stabilized magnetic nanoparticles. The Journal of Physical Chemistry C 116: 5598-5609.

18. Maeng JH, Lee DH, Jung KH, Bae YH, Park IS, et al. (2010) Multifunctional doxorubicin loaded superparamagnetic iron oxide nanoparticles for chemotherapy and magnetic resonance imaging in liver cancer. Biomaterials 31: 4995-5006.

19. Arsalani N, Fattahi H, Nazarpoor M (2010) Synthesis and characterization of PVP-functionalized superparamagnetic $\mathrm{Fe}_{3} \mathrm{O}_{4}$ nanoparticles as an MRI contrast agent. Exp Polym Lett 4: 329-338.

20. Gupta AK, Gupta M (2005) Synthesis and surface engineering of iron oxide nanoparticles for biomedical applications. Biomaterials 26: 3995-4021.

21. Torchilin VP (2006) Nanoparticulates as drug carriers: Imperial college press.

22. Minotti G, Menna P, Salvatorelli E, Cairo G, Gianni L (2004) Anthracyclines: molecular advances and pharmacologic developments in antitumor activity and cardiotoxicity. Pharmacological reviews 56: 185-229.

23. Shen Y, Tang H, Zhan Y, Van Kirk EA, Murdoch WJ (2009) Degradable poly (ß-amino ester) nanoparticles for cancer cytoplasmic drug delivery. Nanomedicine: Nanotechnology, Biology and Medicine 5: 192-201.

24. Aljarrah K, Mhaidat NM, Al-Akhras MAH, Aldaher AN, Albiss BA, et al. (2012) Magnetic nanoparticles sensitize MCF-7 breast cancer cells to doxorubicininduced apoptosis. World journal of surgical oncology 10: 1-5.

25. Mhaidat NM, Alali FQ, Matalqah SM, Matalka II, Jaradat SA, et al. (2009) Inhibition of MEK sensitizes paclitaxel-induced apoptosis of human colorectal cancer cells by downregulation of GRP78. Anti-cancer drugs 20: 601-606. 